\title{
Environmental Friendly Corrosion Inhibitors for Magnesium Alloys
}

\author{
Jinglei LEI ${ }^{1}$, Lingjie $\mathrm{LI}^{1}$ and Fusheng PAN ${ }^{2}$ \\ ${ }^{1}$ Coll. Chem. \& Chem. Eng., Chongqing University \\ ${ }^{2}$ Coll. Mat. Sci. \& Eng., Chongqing University \\ P. R. China
}

\section{Introduction}

Magnesium is an important engineering material because of its light weight and excellent properties. Its density is $1.74 \mathrm{~g} \cdot \mathrm{cm}^{-3}$, only $2 / 3$ that of aluminum and $1 / 4$ that of iron. Moreover, it also has many advantageous properties such as good castability, hot formability, excellent machinability, good electromagnetic shielding characteristics, good biocompatibility, and recyclability (Cao et al, 2006; Staiger et al, 2006). Therefore, magnesium and its alloys have the potential to replace steel and aluminum in many applications. They have already been used in aerospace, aircraft, automotive, mobile electronics, biomaterials and other fields (Zhang \& Zhang, 2004).

However, there are some challenges for applications of magnesium and its alloys in a larger scale. The most important one is improving their poor corrosion resistance. Magnesium is a very active metal, and the standard potential of $\mathrm{Mg}^{2+} / \mathrm{Mg}$ is $-2.356 \mathrm{~V}$ (vs. N.H.E. at $25^{\circ} \mathrm{C}$ ) (Bard \& Faulkner, 2001). Therefore, magnesium and its alloys are extremely susceptible to corrosion, which can cause the decreased mechanical stability and unattractive appearance (Gray \& Luan, 2002). To protect magnesium and its alloys from being corroded, the following techniques are frequently used (Zhang \& Zhang, 2004):

- Conversion surface treatments, as chromating, phosphating, etc.,

- Anodizing,

- Electroplating and electroless plating,

- $\quad$ Adding corrosion inhibitors.

A great number of scientific studies have been devoted to the subjects of the first 3 techniques above (Song, 2005). But the last one, adding corrosion inhibitors has been seldom involved. Inhibitors are chemicals that react with a metallic surface, or the environment this surface is exposed to, giving the surface a certain level of protection (Roberge, 2000). For the metals widely employed in the industry such as iron, copper, zinc and aluminum, adding corrosion inhibitors is an effective and convenient method to decrease the corrosion rate. For magnesium and its alloys, there are very few publications on their corrosion inhibitors and only few inhibitors such as the salts of $\mathrm{F}^{-}$(Song, 2005), $\mathrm{Cr}_{2} \mathrm{O}_{7}^{2-}$ (Song, 2006), 8hydroxyquinoline (Galio et al, 2010), and so on, are involved. Since F- and $\mathrm{Cr}_{2} \mathrm{O}_{7}{ }^{2-}$ pollute the environment seriously, it is quite necessary to pay more attention to develop the environmental friendly corrosion inhibitors for magnesium and its alloys. 
In this chapter, we briefly show our recent research progress in the environmental friendly corrosion inhibitors, sodium benzoate (SB) and sodium dodecylbenzenesulphonate (SDBS), for AZ31 magnesium alloy, an important and widely used magnesium alloy, in an aggressive medium, $3.5 \% \mathrm{NaCl}$ solution. In comparison with the traditional inhibitors of the salts of $\mathrm{F}^{-}$and $\mathrm{Cr}_{2} \mathrm{O}_{7}{ }^{2-}$, these green inhibitors, $\mathrm{SB}$ and SDBS, are promising widely used for magnesium alloys because of their advantages of high inhibition efficiency and harmless to the environment. Our research provides a basis for understanding their anti-corrosion mechanism and indicates the potential approaches for improving the corrosion inhibition efficiency.

\section{Corrosion of $\mathrm{AZ31}$ magnesium alloy in $3.5 \% \mathrm{NaCl}$ solution}

\subsection{Electrochemical impedance spectra (EIS) measurements}

In general, the corrosion resistance of magnesium alloys is less than that of aluminum alloys because the oxide layer on the magnesium alloys is not compact (Zhang \& Zhang, 2004; Song, 2006). When a magnesium alloy contacts some aggressive media such as the solution contains $\mathrm{Cl}$, the aggressive media will penetrate the oxide layer, reach the surface of the alloy and react with the metal substrate, which leads to the occurrence of corrosion. Usually, the rates of the penetration and chemical reactions increase upon the temperature rising. As the results, the corrosion at higher temperature is more serious than that at low temperature. To obtain some information about the corrosion and the influence of the temperature on the corrosion, the electrochemical impedance spectra (EIS) of AZ31 magnesium alloy samples in $3.5 \% \mathrm{NaCl}$ solution at different temperatures were recorded and showed in Fig.1. The EIS were acquired at open circuit potential (OCP) after the samples exposed to the $\mathrm{NaCl}$ solution for $1 \mathrm{~h}$.

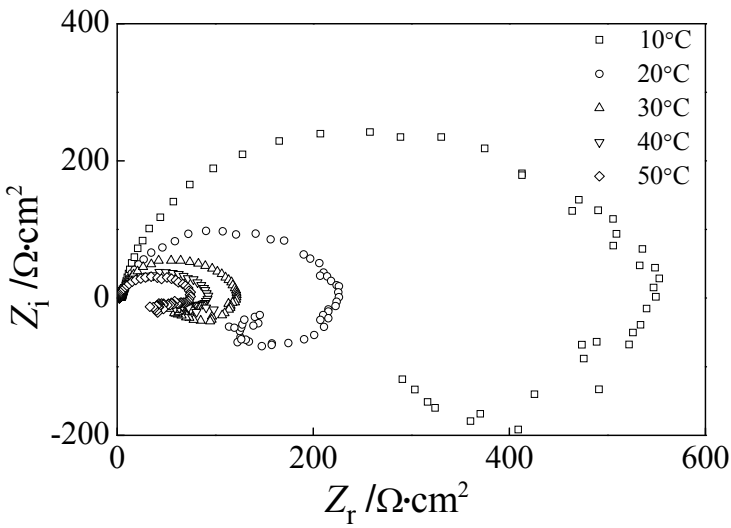

Fig. 1. EIS of AZ31 magnesium alloy in $3.5 \% \mathrm{NaCl}$ solution without inhibitors at different temperatures.

From Fig.1, it could be observed that EIS at every experimental temperature comprised a capacitive resistance loop at high and medium frequency and an inductance loop at low frequency. Generally, the capacitive loop in the high and medium frequency region reflects the information of resistance capacitance relaxation process that related to the charge transfer resistance $R_{\mathrm{t}}$ and the electric double layer capacity $C_{\mathrm{dl}}$; the inductance loop in the low frequency region may be attributed to the instability of the electrode surface when the 
aggressive ions such as $\mathrm{Cl}^{-}$were adsorbed (Cao \& Zhang, 2002). It also could be found, from Fig.1, that the shape of all EIS at different temperatures was almost the same and the diameters of the capacitive resistance loops at high frequency region decreased with the temperature rising. This meant that the temperature only had a little influence on the mechanism of AZ31 magnesium alloy and the serious corrosion occured under the high temperature condition.

To determine quantitatively the impedance parameters of AZ31 magnesium alloy in the $3.5 \% \mathrm{NaCl}$ solution, the capacitive loop in the high and medium frequency range of the measured EIS data were fitted with the equivalent circuit showed in Fig. 2 . In the circuit, the dispersion effect was considered and a constant phase element (CPE) was used to substitute for the capacitive element $C_{\mathrm{dl}}$ (Cao \& Zhang, 2002). Two electrochemical parameters, charge transfer resistance $R_{\mathrm{t}}$ and the double layer capacitance $C P E_{\mathrm{dl}}$ were calculated simultaneously and were listed in Table 1 . The calculated $R_{\mathrm{t}}$ decreased rapidly from 545.6 to $73.34 \Omega \cdot \mathrm{cm}^{2}$ when the temperature was raised from 10 to $50^{\circ} \mathrm{C}$. Generally, $R_{\mathrm{t}}$ is related to the charge transfer reaction and reflects the corrosion resistance of the sample. According to the change of $R_{\mathrm{t}}$, it could be inferred that the corrosion reactions of AZ31 magnesium alloy occurred at high temperature much easier than that at low temperature, which meant that, the magnesium alloy corroded more easily at elevated temperature.

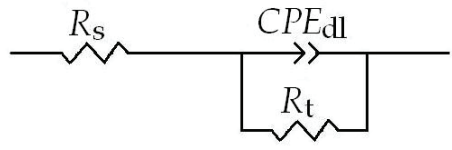

Fig. 2. Equivalent circuit for fitting EIS of AZ31 magnesium alloy in $3.5 \% \mathrm{NaCl}$ solution.

\begin{tabular}{|c|c|c|c|}
\hline$T /{ }^{\circ} \mathrm{C}$ & $R_{\mathrm{t}} / \Omega \cdot \mathrm{cm}^{2}$ & $C P E_{\mathrm{dl}}-\mathrm{T} / \mu \mathrm{F} \cdot \mathrm{cm}^{-2}$ & $C P E_{\mathrm{dl}}-\mathrm{P}$ \\
\hline 10 & 545.6 & 15.49 & 0.9074 \\
\hline 20 & 230.0 & 29.48 & 0.8653 \\
\hline 30 & 121.7 & 29.90 & 0.9123 \\
\hline 40 & 90.00 & 39.18 & 0.9070 \\
\hline 50 & 73.34 & 25.97 & 0.9225 \\
\hline
\end{tabular}

Table 1. Electrochemical parameters obtained by fitting EIS data.

\subsection{Polarization curve measurements}

In Fig.3, the polarization curves of AZ31 magnesium alloy samples in the solution with 3.5\% $\mathrm{NaCl}$ at 10 and $30^{\circ} \mathrm{C}$ were illustrated. The slopes of the anodic branches were very large, which meant that a small increase in the overpotential would lead to a large increase in the anodic current. This phenomenon could be attributed to the poor protection of the surface layer of AZ31 magnesium alloy. When the corrosion reactions take place for magnesium alloys, the reactions can be expressed simply as following (Song, 2006):

$$
\begin{gathered}
\mathrm{Mg} \rightarrow \mathrm{Mg}^{2+}+2 \mathrm{e}^{-} \text {(anodic reaction) } \\
2 \mathrm{H}_{2} \mathrm{O}+2 \mathrm{e}^{-} \rightarrow \mathrm{H}_{2}+2 \mathrm{OH}^{-} \text {(cathodic reaction) } \\
\mathrm{Mg}^{2+}+2 \mathrm{OH}^{-} \rightarrow \mathrm{Mg}(\mathrm{OH})_{2} \text { (product formation) }
\end{gathered}
$$


The unsolvable corrosion product $\mathrm{Mg}(\mathrm{OH})_{2}$ precipitates on the surface of magnesium alloy and form a surface layer. The layer could protect the magnesium alloy from being corroded slightly. However, this protection effect is very poor because that the $\mathrm{Mg}(\mathrm{OH})_{2}$ layer is not compact (Song, 2006). When a corrosive medium containing $\mathrm{Cl}^{-}$contacts with AZ31 magnesium alloy, $\mathrm{Cl}^{-}$, a kind of aggressive ion with small radius, can penetrate this loose $\mathrm{Mg}(\mathrm{OH})_{2}$ layer easily, reach the surface of the magnesium alloy and accelerate the reaction (1). Therefore, the surface layer which composed with the corrosion products $\mathrm{Mg}(\mathrm{OH})_{2}$ only has a little protective function for the magnesium alloys in the solution with $\mathrm{Cl}^{-}$, which led to that the current increased sharply upon the anodic overpotential increasing as if the $\mathrm{Mg}(\mathrm{OH})_{2}$ layer did not exist.

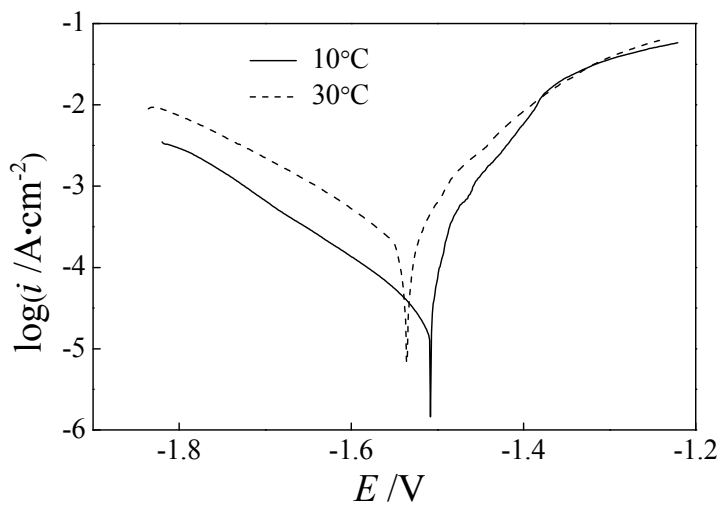

Fig. 3. Polarization curves of AZ31 magnesium alloy samples in the $3.5 \% \mathrm{NaCl}$ solution at 10 and $30^{\circ} \mathrm{C}$.

Compared with the two polarization curves obtained at different temperature in Fig.3, it could be found that the corrosion potential shifted about $30 \mathrm{mV}$ in the negative direction and the corrosion current increased about 10 times when the temperature was raised from 10 to $30^{\circ} \mathrm{C}$. The increased current indicated that the corrosion was more serious at elevated temperature than that at lower temperature, which was in agreement with the results of EIS measurements above.

\section{Inhibition effect of sodium benzoate (SB) for AZ31 magnesium alloy}

Sodium benzoate (SB) is the sodium salt of benzoic acid. Its structure was showed in Fig. 4.<smiles>[NH3+]OC(=O)c1ccccc1</smiles>

Fig. 4. The skeletal chemical structure of SB.

SB has been recognized as safe as a direct food additive for a long time, and also been used as a corrosion inhibitor for steel, zinc, copper, copper alloys, aluminum and aluminum 
alloys (Papavinasam, 2000). Therefore, SB is a kind of environmental friendly corrosion inhibitor. In a corrosion system with the presence of $\mathrm{SB}$, the benzoic acid anion $\mathrm{C}_{6} \mathrm{H}_{5} \mathrm{COO}$ - is adsorbed onto the metal surface via carboxyl groups, which reduces the free energy of the system and impedes the passage of ion-atom of the metal from the lattice into the solution. Sequentially, the corrosion reaction (1) has been inhibited (Afshari \& Dehghanian, 2010). There are many reports which involve the inhibition effect of SB on various metals. However, the inhibition effect of SB on magnesium alloys has rarely been reported.

\subsection{EIS measurements}

Fig.5 showed the EIS results of AZ31 magnesium alloy samples after being exposed to the $3.5 \% \mathrm{NaCl}$ solutions with different concentrations of SB at $20^{\circ} \mathrm{C}$. When the SB concentration was low (less than $0.3 \mathrm{~mol} \cdot \mathrm{L}^{-1}$ ), the main characteristic of EIS was the same as that of the EIS without SB. They were still composed of a capacitive resistance loop at high and medium frequency and an inductance loop at low frequency. The capacitive resistance loop at high and medium frequency enlarged upon the SB concentration increasing, which indicated the increase in the corrosion resistance. When the SB concentration increased to a relative high level (greater than $0.4 \mathrm{~mol} \cdot \mathrm{L}^{-1}$ ), the capacitive resistance loop at high and medium frequency kept in enlarging. However, the inductance loop at low frequency was substituted by a capacitive resistance loop. This capacitive resistance loop at low frequency generally was considered to be related to the adsorption-desorption processes of corrosion inhibitor molecules on the surface of magnesium alloy electrodes (Cao \& Zhang, 2002).

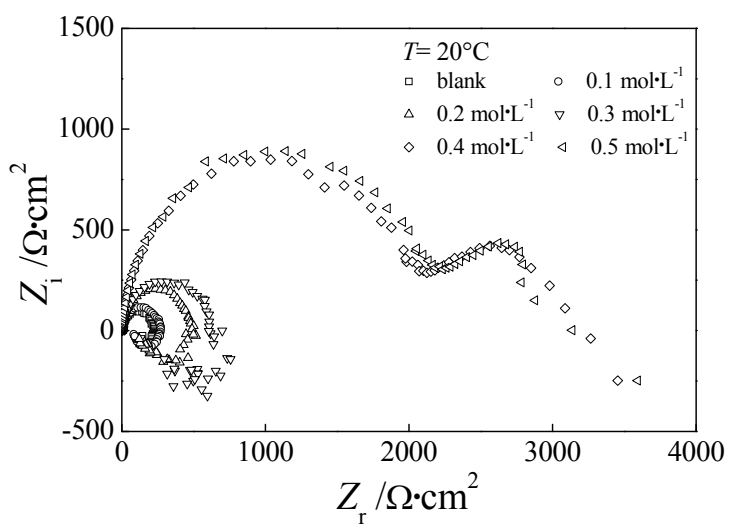

Fig. 5. EIS of AZ31 magnesium alloy in $3.5 \% \mathrm{NaCl}$ solutions with different concentrations of corrosion inhibitor $\mathrm{SB}$ at $20^{\circ} \mathrm{C}$.

By analyzing the capacitive resistance loop in the high and medium frequency range with the equivalent circuit showed in Fig.2, both the charge transfer resistance $R_{\mathrm{t}}$ and the interfacial capacitance $C P E_{\mathrm{dl}}$ were calculated and listed in Table 2.

In Table 2, the corrosion inhibition efficiency $\eta$ was also listed. The values of $\eta$ were calculated according to the following formula:

$$
\eta=\frac{R_{\mathrm{t}}-R_{\mathrm{t}}^{0}}{R_{\mathrm{t}}} \times 100 \%
$$


where $R_{\mathrm{t}}{ }^{0}$ and $R_{\mathrm{t}}$ represent the charge transfer resistance of the system without and with the corrosion inhibitor SB, respectively. The inhibition efficiency $\eta$ reached $88 \%$ till the concentration of SB was $0.4 \mathrm{~mol} \cdot \mathrm{L}^{-1}$, and $\eta$ increased very little when the SB concentration was higher. Therefore, the concentration $0.4 \mathrm{~mol} \cdot \mathrm{L}^{-1}$ could be treated as the "most economic concentration" for SB. Moreover, it should be noted that all $\eta$ in Table 2 were less than $90 \%$, which indicated that SB was not a desirable inhibitor for the magnesium alloys.

\begin{tabular}{|c|c|c|c|c|}
\hline$C_{S \text { B }} / \mathrm{mol} \cdot \mathrm{L}^{-1}$ & $R_{t} / \Omega \cdot \mathrm{cm}^{2}$ & $C P E_{d l}-\mathrm{T} / \mu \mathrm{F} \cdot \mathrm{cm}^{-2}$ & $C P E_{d l}-\mathrm{P}$ & $\eta / \%$ \\
\hline 0 & 230.0 & 29.49 & 0.8653 & - \\
\hline 0.1 & 288.4 & 36.16 & 0.8246 & 20.25 \\
\hline 0.2 & 515.6 & 28.77 & 0.8411 & 55.39 \\
\hline 0.3 & 644.1 & 29.50 & 0.8392 & 64.29 \\
\hline 0.4 & 2005 & 12.54 & 0.9222 & 88.53 \\
\hline 0.5 & 2121 & 13.44 & 0.9215 & 89.16 \\
\hline
\end{tabular}

Table 2. Electrochemical parameters obtained by fitting EIS data and the calculated corrosion inhibition efficiency of $\mathrm{SB}$ at $20^{\circ} \mathrm{C}$.

\subsection{Adsorption isotherm for SB on magnesium alloy}

Assuming that the adsorption process of SB onto the AZ31 magnesium alloy sample surface was governed by Temkin adsorption isotherm, the relationship among the corrosion inhibitor concentration $c$, the adsorption equilibrium constant $K$ and the surface coverage $\theta$ would be (Mu et al, 2005; Sahin \& Bilgic, 1999):

$$
\exp (-2 \alpha \theta)=K c
$$

where $\alpha$ is the molecular interaction parameter, which represents the interaction among the different substances in the adsorptive layer. When $\alpha=0$, there is no interaction between the adsorptive substances; when $\alpha>0$ or $\alpha<0$, there exists attractive or repulsive force among the adsorptive substances, respectively. Formula (5) could be converted into formula (6) as following:

$$
\ln c=-2 \alpha \theta-\ln K
$$

To simply the calculation, the coverage $\theta$ could be substituted approximatively by the corrosion inhibition efficiency $\eta$ (Cao \& Zhang, 2002). Thus, the relationship between $c$ and $\eta$ was fitted as a linear function and the results were showed in Fig. 6 . The linear correlation coefficient of the fitting was 0.981 , very close to 1 , which indicated that our assumption about the adsorption process was correct, which meant that, the adsorption of SB on AZ31 magnesium alloy obeyed Temkin adsorption isotherm.

The adsorption equilibrium constant $K$ was $15.61 \mathrm{~L} \cdot \mathrm{mol}^{-1}$, which was calculated from the intercept of the fitted straight line in Fig.6. The value of $\alpha$, calculated from the slope of the fitted line, was -1.104 . The negative sign of $\alpha$ suggested that the intermolecular repulsion existed among the adsorbed SB molecules on the surface of AZ31 magnesium alloy sample. The repulsion is a possible reason for the large dosage of SB and the undesirable corrosion inhibition efficiency. 


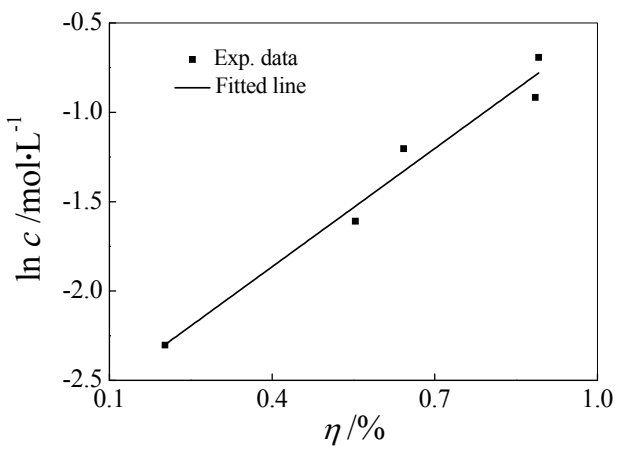

Fig. 6. The relationship between $\ln c-\eta$ for the adsorption of $\mathrm{SB}$ at $20^{\circ} \mathrm{C}$.

\subsection{Influence of the temperature on the inhibition effect of SB}

To investigate the influence of the temperature on the inhibition effect of SB for AZ31 magnesium alloys, the temperature of the medium was cooled to $10^{\circ} \mathrm{C}$. The EIS were illustrated in Fig. 7. Since the main characteristic of EIS in Fig. 7 was the same as that in Fig.5, the same equivalent circuit, showed in Fig.2, could be used to fit the EIS. The charge transfer resistance $R_{\mathrm{t}}$ and the interfacial capacitance $C P E_{\mathrm{dl}}$ were calculated and listed in Table 3, then the corrosion inhibition efficiency $\eta$ was obtained with the formula (4), too.

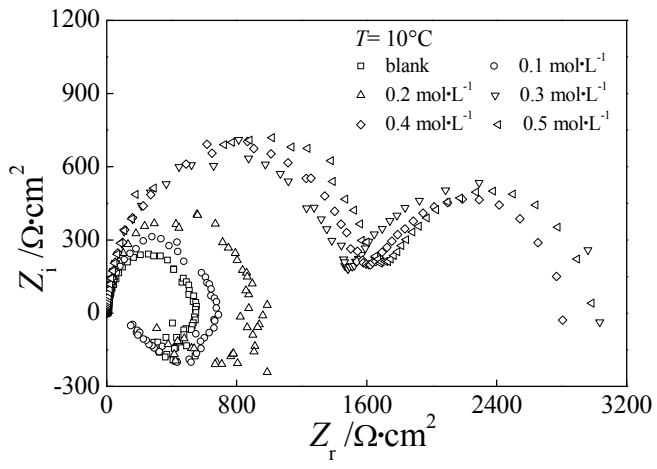

Fig. 7. EIS of AZ31 magnesium alloy in $3.5 \% \mathrm{NaCl}$ solutions with different concentrations of corrosion inhibitor $\mathrm{SB}$ at $10^{\circ} \mathrm{C}$.

\begin{tabular}{|c|c|c|c|c|}
\hline$c_{\mathrm{SB}} / \mathrm{mol} \cdot \mathrm{L}^{-1}$ & $R_{\mathrm{t}} / \Omega \cdot \mathrm{cm}^{2}$ & $C P E_{\mathrm{dl}}-\mathrm{T} / \mu \mathrm{F} \cdot \mathrm{cm}^{-2}$ & $C P E_{\mathrm{dl}}-\mathrm{P}$ & $\eta / \%$ \\
\hline 0 & 545.6 & 15.49 & 0.9074 & - \\
\hline 0.1 & 674.3 & 13.54 & 0.9051 & 19.09 \\
\hline 0.2 & 910.1 & 10.86 & 0.9316 & 40.06 \\
\hline 0.3 & 1467 & 12.55 & 0.9227 & 62.81 \\
\hline 0.4 & 1593 & 12.08 & 0.9268 & 65.75 \\
\hline 0.5 & 1695 & 10.82 & 0.9423 & 67.81 \\
\hline
\end{tabular}

Table 3. Electrochemical parameters obtained by fitting EIS data and the calculated corrosion inhibition efficiency of $\mathrm{SB}$ at $10^{\circ} \mathrm{C}$. 
The values of the corrosion inhibition efficiency $\eta$ in Table 3 were greater those that in Table 2 , which indicated that the elevated temperature was helpful to inhibit the corrosion of magnesium alloys.

By using the same procedure as that to deal with the data at $20^{\circ} \mathrm{C}$, the linear relationship between $\ln c-\eta$ at $10^{\circ} \mathrm{C}$ was drawn in Fig. 8 (the correlation coefficient of the fitting was 0.970), and the parameters of Temkin adsorption isotherm (molecular interaction parameter $\alpha=-1.474$, adsorption equilibrium constant $K=17.31 \mathrm{~L} \cdot \mathrm{mol}^{-1}$ ) were obtained.

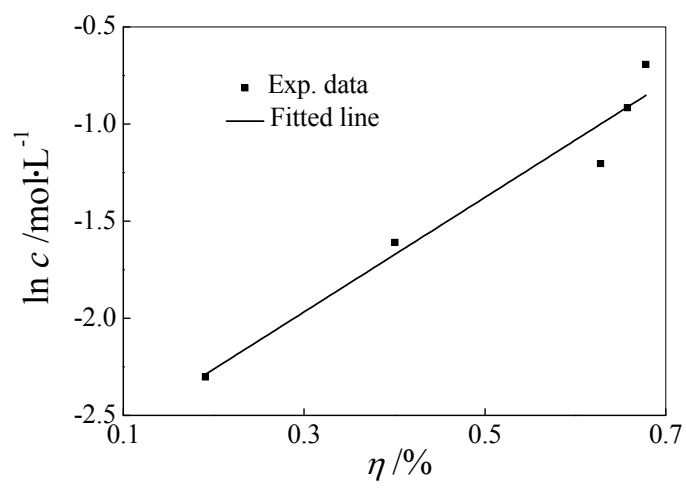

Fig. 8. The relationship between $\ln c-\eta$ for the adsorption of $\mathrm{SB}$ at $10^{\circ} \mathrm{C}$.

\subsection{Thermodynamic parameters for adsorption of SB on magnesium alloy}

Thermodynamic model is very helpful to understand the adsorption phenomenon of inhibitor molecules. By using the obtained adsorption equilibrium constant above, the adsorption free energy, adsorption heat and adsorption entropy can be calculated based on the Van't Hoff equation of physical chemistry (Atkins \& Paula, 2006):

$$
\ln K=\frac{-\Delta H}{R T}+\text { Constant }
$$

where $\Delta H$ is the adsorption heat. Obviously, the relationship between $\ln K$ and $1 / T$ could be described as a linear function, hence $\Delta H$ could be obtained from the slope of the straight line. Fig. 9 showed the linear relationship between $\ln K$ and $1 / T$, and the adsorption heat was calculated as $-4.296 \mathrm{~kJ} \cdot \mathrm{mol}^{-1}$. Under the experimental conditions, the adsorption heat can be approximately regarded as the standard adsorption heat $\Delta H^{0}$ (Mu et al, 2005).

To obtain the standard adsorption free energy $\Delta G^{0}$, the following equation was employed (Mu et al, 2005):

$$
K=\frac{1}{55.5} \exp \left(\frac{-\Delta G^{0}}{R T}\right)
$$

where the value of 55.5 is the concentration of water in solution expressed in mol.L-1.

Then the standard adsorption entropy $\Delta S^{0}$ could be calculated based on the thermodynamic basic equation (9):

$$
\Delta G^{0}=\Delta H^{0}-T \Delta S^{0}
$$




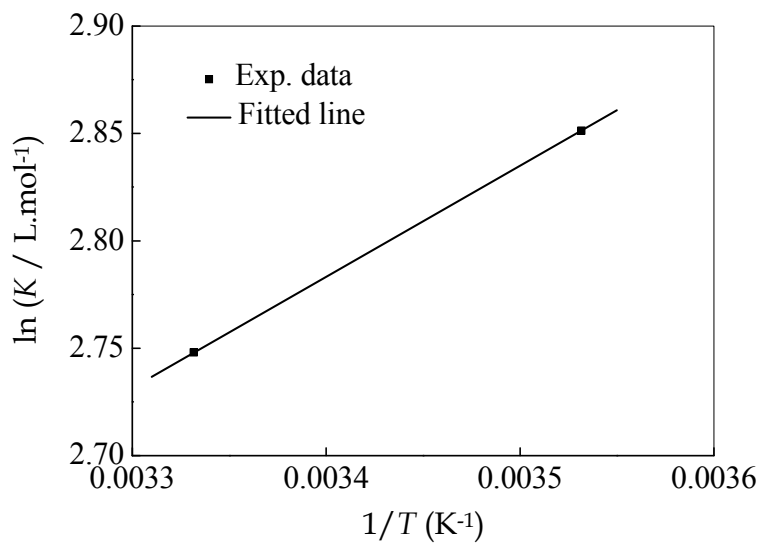

Fig. 9. The relationship between $\ln K$ and $1 / T$ for the adsorption of SB.

All the calculated thermodynamic parameters were listed in Table 4.

\begin{tabular}{|c|c|c|c|}
\hline$T /{ }^{\circ} \mathrm{C}$ & $\Delta H^{0} / \mathrm{kJ} \cdot \mathrm{mol}^{-1}$ & $\Delta G^{0} / \mathrm{kJ} \cdot \mathrm{mol}^{-1}$ & $\Delta S^{0} / \mathrm{J} \cdot \mathrm{mol}^{-1} \cdot \mathrm{K}^{-1}$ \\
\hline 10 & -4.296 & -16.17 & 41.92 \\
\hline 20 & -4.296 & -16.48 & 41.58 \\
\hline
\end{tabular}

Table 4. Calculated thermodynamic parameters for the adsorption of SB on AZ31 magnesium alloy surface at 10 and $20^{\circ} \mathrm{C}$.

The negative value of $\Delta H^{0}$ indicates that the adsorption of SB is an exothermic process. And according to the magnitude of $\Delta H^{0}$, it seems reasonable to assume that physical adsorption takes place for SB on AZ31 magnesium alloy surface. The negative value of $\Delta G^{0}$ means that the adsorption of SB on AZ31 magnesium alloy surface is a spontaneous process. The positive values of $\Delta S^{0}$ suggest that the adsorption is a process accompanied by an increase in entropy. The increased entropy might be related to that the repulsive force exists among the adsorptive molecules of corrosion inhibitor $\mathrm{SB}$, which leads to the disordered arrangement of SB molecules on AZ31 magnesium alloy surface.

\subsection{Polarization curve measurements}

Polarization curve experiments can provide an insight into the mechanism of the SB corrosion inhibition effect. Since the temperature has a little influence on the EIS results, here we only show the potentiodynamic polarization curves of AZ31 magnesium alloy in $3.5 \% \mathrm{NaCl}$ solutions with and without additions of $0.5 \mathrm{~mol} \cdot \mathrm{L}^{-1} \mathrm{SB}$ at $10^{\circ} \mathrm{C}$ in Fig. 10 .

The corrosion potential $E_{\text {corr }}$ and pitting potential $E_{\text {pit }}$ were marked in Fig. 10 . In $3.5 \% \mathrm{NaCl}$ solution without $\mathrm{SB}, E_{\text {pit }}$ of AZ31 magnesium alloy was more negative than $E_{\text {corr, }}$ which was similar to the result reported in the literature (Song \& Atrens, 2003). This indicated that pitting occurred spontaneously when AZ31 magnesium alloy contacted with the aggressive medium, which meant that AZ31 magnesium alloy was unstable in the $\mathrm{NaCl}$ solution. When the solution contained $\mathrm{SB}, E_{\text {corr }}$ was more negative than $E_{\text {pit. }}$. It also could be observed that $E_{\text {corr }}$ shifted in the positive direction about $20 \mathrm{mV}$ after SB was added into the solution. Moreover, compared with the situation without SB in the solution, the current density of anodic branch decreased obviously while the cathodic branch current density only changed little. 


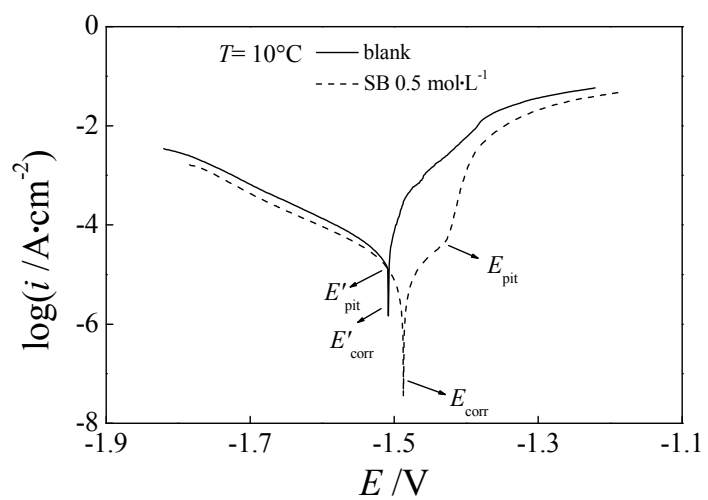

Fig. 10. Polarization curves of AZ31 magnesium alloy samples in $3.5 \% \mathrm{NaCl}$ solutions with and without $\mathrm{SB}$ at $10^{\circ} \mathrm{C}$.

Therefore, it could be inferred that SB was a kind of anodic corrosion inhibitor for AZ31 magnesium alloy.

\subsection{Scanning electron microscope (SEM) characterization}

To observe the inhibition effect of SB directly, the surface morphology of AZ31 magnesium alloy samples was acquired with Scanning Electron Microscope (SEM) and showed in Fig. 11. Before the SEM observations, the magnesium alloy samples had been immersed in the $3.5 \% \mathrm{NaCl}$ solution contained SB $0.4 \mathrm{~mol} \cdot \mathrm{L}^{-1}$ at $\mathrm{OCP}$ at $30^{\circ} \mathrm{C}$ for $1 \mathrm{~h}$. As the comparison, the SEM image of surface morphology of the sample exposed to the solution without SB at OCP for $1 \mathrm{~h}$ was also acquired and showed in Fig. 11 (a). The image of Fig. 11 (a) indicated that the serious corrosion occurred, the corrosion products covered the sample surface and there were many cracks in the surface layer of the products. In Fig. 11 (b), the sample surface after immersion test in SB solution was still very smooth, which meant that SB inhibited the corrosion of AZ31 magnesium alloy effectively.

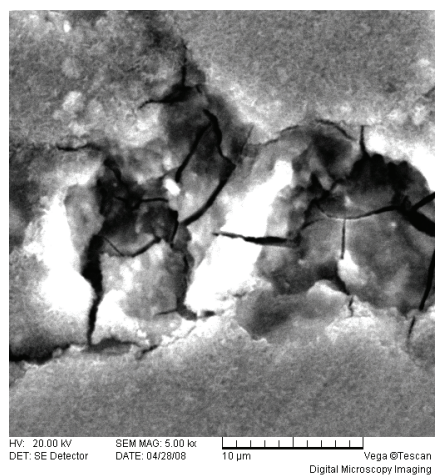

(a)

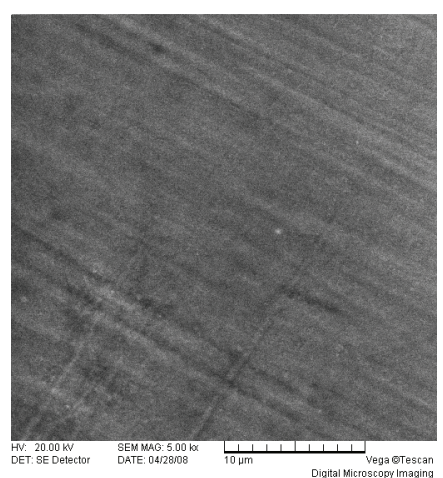

(b)

Fig. 11. SEM images of AZ31 magnesium alloy samples after $1 \mathrm{~h}$ immersion at $30^{\circ} \mathrm{C}$ in the solutions contained (a) no inhibitors; (b) $0.4 \mathrm{~mol} \cdot \mathrm{L}^{-1} \mathrm{SB}$. 


\section{Inhibition effect of sodium dodecylbenzenesulfonate (SDBS) for AZ31 magnesium alloy}

The structure of sodium dodecylbenzenesulfonate (SDBS) was showed in Fig. 12. SDBS is an anionic surfactant with good biological degradability and usually used to produce industrial and daily detergents. It has also been recognized as a kind of environmental friendly corrosion inhibitor for some metals and alloys. However, besides our work (Li et al, 2009), there are few reports on its inhibition effect for magnesium alloys.<smiles>CCCCc1ccc(S(=O)(=O)O[Na])cc1</smiles>

Fig. 12. The skeletal chemical structure of SDBS.

\subsection{EIS measurements}

Fig. 13 and Fig. 14 showed the EIS of AZ31 magnesium alloy samples, which were acquired in the $3.5 \% \mathrm{NaCl}$ solutions with different concentration of SDSB at 30 and $50^{\circ} \mathrm{C}$ respectively.

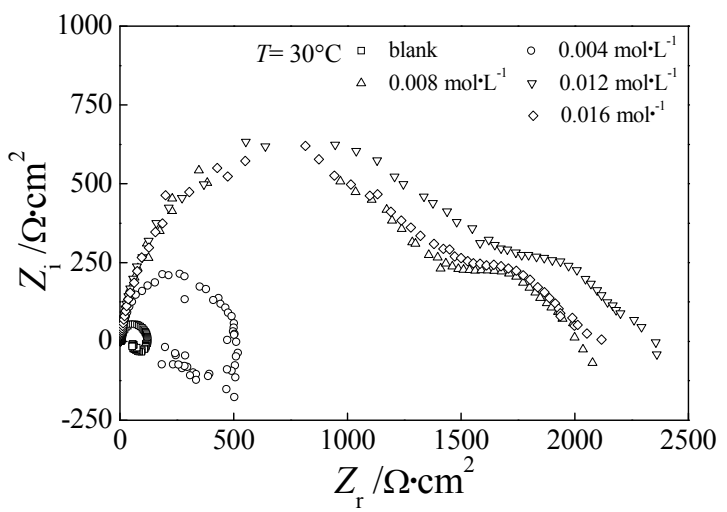

Fig. 13. EIS of AZ31 magnesium alloy in $3.5 \% \mathrm{NaCl}$ solutions with different concentrations of corrosion inhibitor SDBS at $30^{\circ} \mathrm{C}$.

The main characteristic of EIS, including a capacitive resistance loop at high and medium frequency and an inductance loop at low frequency, was the same as that of the EIS with SB, which were illustrated in Fig. 5. Therefore, the equivalent circuit in Fig.2, which was used to analyze the EIS with SB, could also be used to fit the EIS data here. Both the charge transfer resistance $R_{\mathrm{t}}$ and the interfacial capacitance $C P E_{\mathrm{dl}}$ were calculated and listed in Table 5 and Table 6, respectively. Moreover, the corrosion inhibition efficiency $\eta$ was obtained with the formula (4) and listed in the tables, too. Obviously, the "most economic concentration" of SDBS was $0.008 \mathrm{~mol} \cdot \mathrm{L}^{-1}$. Compared with SB, whose "most economic concentration" was 0.4 mol. $\mathrm{L}^{-1}$ and the highest inhibition efficiency was less than $90 \%$, SDBS was a better inhibitor for AZ31 magnesium alloy because of the lower dosage and higher inhibition efficiency. 


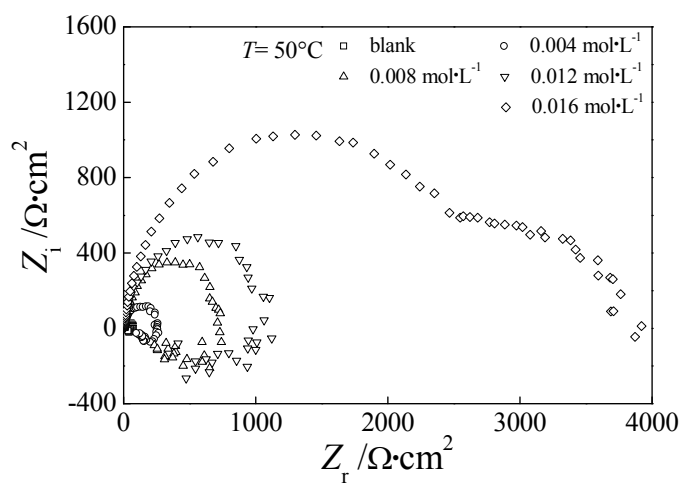

Fig. 14. EIS of AZ31 magnesium alloy in $3.5 \% \mathrm{NaCl}$ solutions with different concentrations of corrosion inhibitor SDBS at $50^{\circ} \mathrm{C}$.

\begin{tabular}{|c|c|c|c|c|}
\hline$C_{S D B S} / \mathrm{mol} \cdot \mathrm{L}^{-1}$ & $R_{\mathrm{t}} / \Omega \cdot \mathrm{cm}^{2}$ & $C P E_{\mathrm{dl}}-\mathrm{T} / \mu \mathrm{F} \cdot \mathrm{cm}^{-2}$ & $C P E_{\mathrm{dl}}-\mathrm{P}$ & $\eta / \%$ \\
\hline 0 & 121.7 & 29.91 & 0.9123 & - \\
\hline 0.004 & 510.1 & 16.24 & 0.8867 & 76.14 \\
\hline 0.008 & 1442 & 13.83 & 0.8871 & 91.56 \\
\hline 0.012 & 1597 & 13.22 & 0.8889 & 92.38 \\
\hline 0.016 & 1512 & 15.80 & 0.8715 & 91.95 \\
\hline
\end{tabular}

Table 5. Electrochemical parameters obtained by fitting EIS data and the calculated corrosion inhibition efficiency of SDBS at $30^{\circ} \mathrm{C}$.

\begin{tabular}{|c|c|c|c|c|}
\hline$c_{\text {SDBS }} / \mathrm{mol} \cdot \mathrm{L}^{-1}$ & $R_{\mathrm{t}} / \Omega \cdot \mathrm{cm}^{2}$ & $C P E_{\mathrm{dl}}-\mathrm{T} / \mu \mathrm{F} \cdot \mathrm{cm}^{-2}$ & $C P E_{\mathrm{dl}}-\mathrm{P}$ & $\eta / \%$ \\
\hline 0 & 73.34 & 25.97 & 0.9225 & - \\
\hline 0.004 & 278.4 & 20.29 & 0.8777 & 73.66 \\
\hline 0.008 & 767.1 & 9.807 & 0.9243 & 90.44 \\
\hline 0.012 & 1115 & 11.39 & 0.8932 & 93.42 \\
\hline 0.016 & 2557 & 11.00 & 0.8967 & 97.13 \\
\hline
\end{tabular}

Table 6. Electrochemical parameters obtained by fitting EIS data and the calculated corrosion inhibition efficiency of SDBS at $50^{\circ} \mathrm{C}$.

It should be noted that the temperature only had little influence on the corrosion inhibition efficiency of SDBS based on the calculated values in Table 5 and Table 6.

\subsection{Adsorption isotherm and adsorption thermodynamic parameters for SDBS on magnesium alloy}

By testing graphically, it was found that Langmuir adsorption isotherm described the relationship between the surface coverage value $\theta$ and the concentration of the corrosion inhibitor SDBS perfectly:

$$
\frac{c}{\theta}=\frac{1}{K}+c
$$


where $K$ denoted the adsorption equilibrium constant. Here the coverage $\theta$ also was substituted by the corrosion inhibition efficiency $\eta$ approximately to simply the calculation. According to the equation (10), linear regressions between $c / \theta$ and $c$ at 30 and $50^{\circ} \mathrm{C}$ were carried out and the results were illustrated in Fig. 15 and Fig. 16, respectively. The slopes of the straight lines, the linear correlation coefficients and the equilibrium constants $K$ were listed in Table 7.

In Table 7, the slopes of the straight lines, the linear correlation coefficients were very close to 1, which confirmed that the adsorption of inhibitor SDBS onto AZ31 magnesium alloy surface was governed by the Langmuir adsorption isotherm.

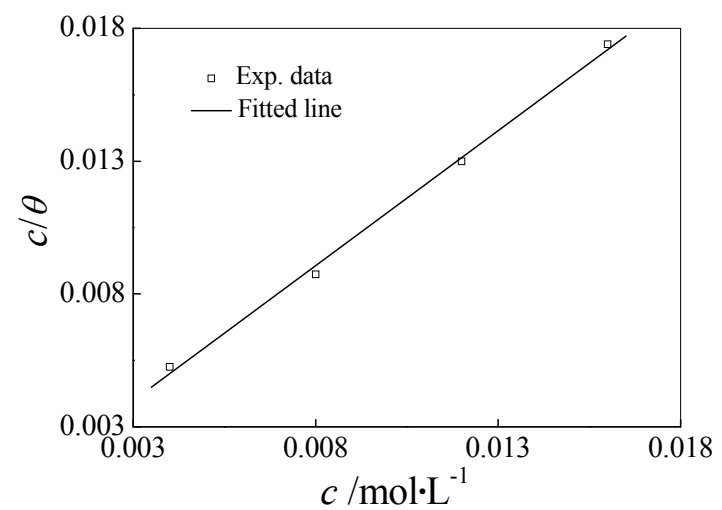

Fig. 15. The relationship between $c / \theta-c$ for the adsorption of SDBS at $30^{\circ} \mathrm{C}$.

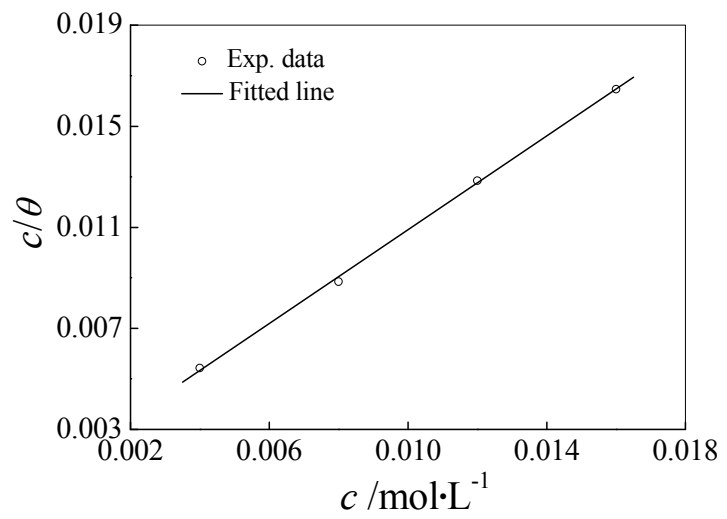

Fig. 16. The relationship between $c / \theta-c$ for the adsorption of SDBS at $50^{\circ} \mathrm{C}$.

\begin{tabular}{|c|c|c|c|}
\hline $\mathrm{T} /{ }^{\circ} \mathrm{C}$ & $\mathrm{K} / \mathrm{L} \cdot \mathrm{mol}^{-1}$ & Slope & $r$ \\
\hline 30 & 1085 & 1.017 & 0.996 \\
\hline 50 & 617.3 & 0.9282 & 0.999 \\
\hline
\end{tabular}

Table 7. Linear regression parameters of $c / \theta-c$ for the adsorption of SDBS. 


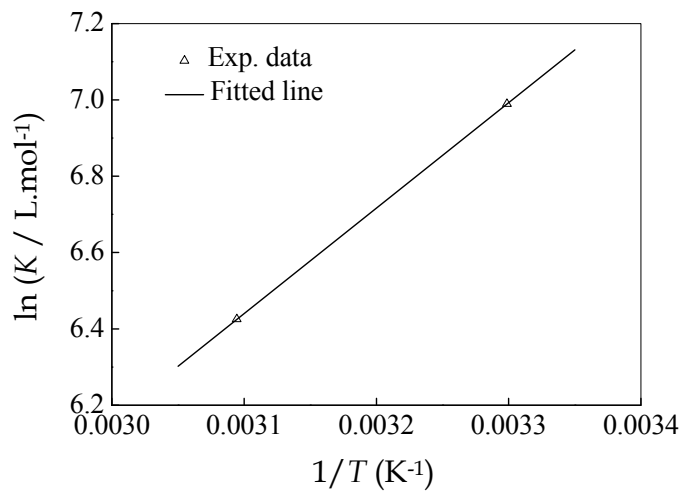

Fig. 17. The relationship between $\ln K$ and $1 / T$ for the adsorption of SDBS.

Using the values of $K$ in Table 7, a linear relationship between $\ln K$ and $1 / T$, which were used to calculate standard adsorption heat $\Delta H^{0}$ based on the formula (7), were obtained and illustrated in Fig. 17. Then, the standard adsorption free energy $\Delta G^{0}$ and standard adsorption entropy $\Delta S^{0}$ were calculated with the formulas (8) - (9) and given in Table 8.

\begin{tabular}{|c|c|c|c|}
\hline $\mathrm{T} /{ }^{\circ} \mathrm{C}$ & $\Delta H^{0} / \mathrm{kJ} \cdot \mathrm{mol}^{-1}$ & $\Delta \mathrm{G}^{0} / \mathrm{kJ} \cdot \mathrm{mol}^{-1}$ & $\Delta S^{0} / \mathrm{J} \cdot \mathrm{mol}^{-1} \cdot \mathrm{K}^{-1}$ \\
\hline 30 & -22.96 & -35.43 & 41.14 \\
\hline 50 & -22.96 & -37.77 & 45.82 \\
\hline
\end{tabular}

Table 8. Calculated thermodynamic parameters for the adsorption of SDBS on AZ31 magnesium alloy surface at 30 and $50^{\circ} \mathrm{C}$.

According to the value of $\Delta H^{0}$, it could be inferred that the adsorption of SDBS on AZ31 magnesium alloy surface is an exothermic process and belongs to the physical adsorption. The negative value of $\Delta G^{0}$ indicates that the adsorption of SDBS onto AZ31 magnesium alloy surface is a spontaneous process. The positive values of $\Delta S^{0}$ suggest that the adsorption is a process accompanied by an increase in entropy.

\subsection{Polarization curve measurements}

The polarization behaviors of AZ31 magnesium alloy samples in $3.5 \% \mathrm{NaCl}$ solutions without and with $0.012 \mathrm{~mol} \cdot \mathrm{L}^{-1} \mathrm{SDBS}$ at $30^{\circ} \mathrm{C}$ were showed in Fig. 18. The presence of SDBS in the solution led to that corrosion potential $E_{\text {corr }}$ shifted in the positive direction about 15 $\mathrm{mV}$ and $E_{\text {corr }}$ was more negative than the pitting potential $E_{\text {pit. }}$ Moreover, the current densities of both the anodic and cathodic branch decreased, it could be inferred that SDBS is a kind of mixed corrosion inhibitor for AZ31 magnesium alloy.

\subsection{SEM characterization}

SEM technique was used to characterize the surface morphology of AZ31 magnesium alloy samples. After being exposed to the $3.5 \% \mathrm{NaCl}$ solution with $0.012 \mathrm{~mol} \cdot \mathrm{L}^{-1} \mathrm{SDBS}$ for $1 \mathrm{~h}$, the sample still had a smooth surface, which was given in Fig. 19. Compared with the rough surface of the sample immersed in the solution without any corrosion inhibitors, (illustrated in Fig. 11 (a)), it could be concluded that SDBS was an effective corrosion inhibitor for AZ31 magnesium alloy. 


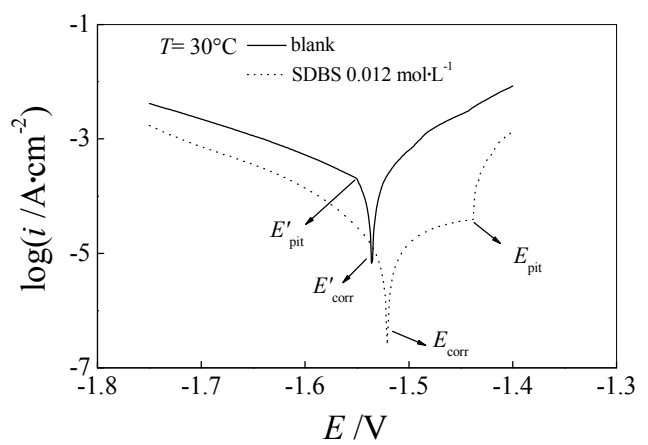

Fig. 18. Polarization curves of AZ31 magnesium alloy samples in $3.5 \% \mathrm{NaCl}$ solutions without and with $0.012 \mathrm{~mol} \cdot \mathrm{L}^{-1} \mathrm{SDBS}$ at $30^{\circ} \mathrm{C}$.

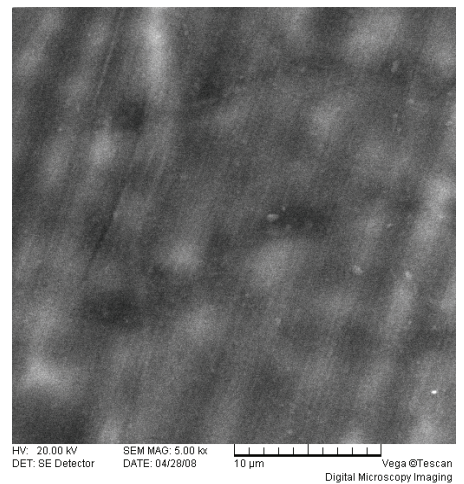

Fig. 19. SEM image of AZ31 magnesium alloy simple after $1 \mathrm{~h}$ immersion at $30^{\circ} \mathrm{C}$ in the solution contained $0.012 \mathrm{~mol} \cdot \mathrm{L}^{-1}$ SDBS.

\section{Comparison of the effect of inhibitors for AZ31 magnesium alloy}

To evaluate the corrosion inhibition effect of SB and SDBS, their inhibition efficiency was compared with that of the salts of $\mathrm{F}^{-}$and $\mathrm{Cr}_{2} \mathrm{O}_{7}{ }^{2-}$. The salts chosen here were $\mathrm{KF}$ and $\mathrm{K}_{2} \mathrm{Cr}_{2} \mathrm{O}_{7}$, the widely used corrosion inhibitors for magnesium alloys at present (Song, 2005; Song, 2006).

First, polarization curve measurements were carried out. Fig. 20 illustrated the polarization curves for AZ31 magnesium alloy samples in the 3.5\% $\mathrm{NaCl}$ solutions contained one of the inhibitors of $\mathrm{SB}$, SDBS, $\mathrm{KF}$ and $\mathrm{K}_{2} \mathrm{Cr}_{2} \mathrm{O}_{7}$ at $30^{\circ} \mathrm{C}$, respectively.

Since the negative difference effect (NDE) exists for magnesium alloys (Song \& Atrens, 2003), the corrosion current density calculated from the polarization curve is not reliable. Here we only analyzed the polarization curves qualitatively. In Fig. 20, it could be observed that the current decreased with the presence of the inhibitors, which suggested that every inhibitors studied here could inhibit the corrosion of magnesium alloy effectively. According to the shifts of the corrosion potential, it could be inferred that SDBS, KF and $\mathrm{K}_{2} \mathrm{Cr}_{2} \mathrm{O}_{7}$ were mixed inhibitors while $\mathrm{SB}$ was an anodic inhibitor for magnesium alloys. 


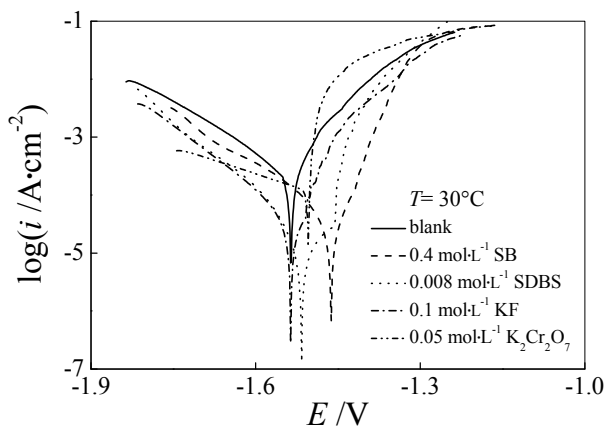

Fig. 20. Polarization curves of AZ31 magnesium alloy samples in $3.5 \% \mathrm{NaCl}$ solutions with different inhibitors at $30^{\circ} \mathrm{C}$.

EIS technique was also employed to evaluate the inhibition effect. Fig. 21 showed the EIS of AZ31 magnesium alloy in $3.5 \% \mathrm{NaCl}$ solutions without and with the different corrosion inhibitors at $30^{\circ} \mathrm{C}$. The capacitive resistance loop at high and medium frequency enlarged obviously upon the presence of the inhibitors, which indicated that all inhibitors reduce the corrosion of AZ31 magnesium alloy effectively. The results of EIS and polarization curve measurements were in good agreement qualitatively. Moreover, by fitting the EIS data in the high and medium frequency range with the equivalent circuit showed in Fig.2, the values showed in charge transfer resistance $R_{\mathrm{t}}$ and other electrochemical parameters could be calculated quantitatively. Table 9 listed the electrochemical parameters obtained by fitting EIS data and the corrosion inhibition efficiency $\eta$ calculated with the formula (4).

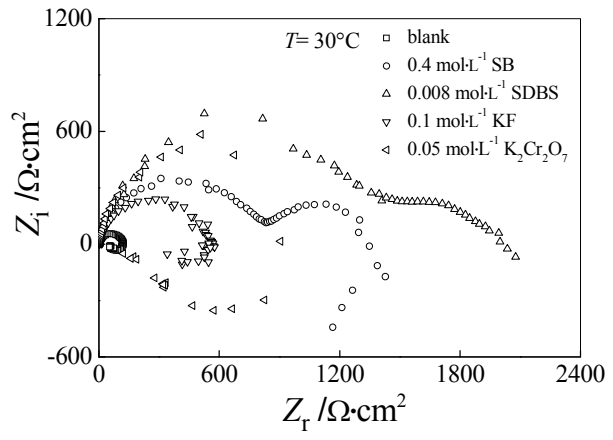

Fig. 21. EIS of AZ31 magnesium alloy samples in $3.5 \% \mathrm{NaCl}$ solutions with different inhibitors at $30^{\circ} \mathrm{C}$.

\begin{tabular}{|cc|c|c|c|c|}
\hline \multicolumn{2}{|c|}{$c_{\text {inhibitor }} / \mathrm{mol} \cdot \mathrm{L}^{-1}$} & $R_{\mathrm{t}} / \Omega \cdot \mathrm{cm}^{2}$ & $C P E_{\mathrm{dl}}-\mathrm{T} / \mu \mathrm{F} \cdot \mathrm{cm}^{-2}$ & $C P E_{\mathrm{dl}}-\mathrm{P}$ & $\eta / \%$ \\
\hline 0 & & 121.70 & 29.91 & 0.9123 & - \\
\hline $0.4 \mathrm{~mol} \cdot \mathrm{L}^{-1}$ & SB & 818.40 & 15.73 & 0.9114 & 85.13 \\
\hline $0.008 \mathrm{~mol} \cdot \mathrm{L}^{-1}$ & $\mathrm{SDBS}$ & 1442.0 & 13.83 & 0.8870 & 91.56 \\
\hline $0.1 \mathrm{~mol} \cdot \mathrm{L}^{-1}$ & $\mathrm{KF}$ & 557.10 & 10.26 & 0.8677 & 78.15 \\
\hline $0.05 \mathrm{~mol} \cdot \mathrm{L}^{-1}$ & $\mathrm{~K}_{2} \mathrm{Cr}_{2} \mathrm{O}_{7}$ & 1054.0 & 73.38 & 0.9636 & 88.45 \\
\hline
\end{tabular}

Table 9. Electrochemical parameters obtained by fitting EIS data and the calculated corrosion and inhibition efficiency of different inhibitors at $30^{\circ} \mathrm{C}$. 
Based on the polarization curves in Fig. 20 and the corrosion inhibition efficiency $\eta$ in Table 9, the sort order of the corrosion inhibition efficiency for the different inhibitors should be:

$$
\eta_{\mathrm{SDBS}}>\eta_{\mathrm{Cr}_{2} \mathrm{O}_{7}^{2-}}>\eta_{\mathrm{SB}}>\eta_{\mathrm{F}^{-}}
$$

Considering the toxicity of $\mathrm{F}^{-}$and $\mathrm{Cr}_{2} \mathrm{O}_{7}{ }^{2-}$, SDBS and SB are promising widely used for magnesium alloys because of their advantages of high inhibitive efficiency and environmental friendly property.

\section{Conclusions}

In this chapter, EIS, potentiodynamic polarization and SEM measurements were conducted to study the effect of environmental friendly corrosion inhibitors of SB and SDBS on the AZ31 magnesium alloy in 3.5\% NaCl solutions. Our investigations show that both $\mathrm{SB}$ and SDBS are the effective inhibitors for magnesium alloys, which provides a basis for understanding their anti-corrosion performance and indicates the potential approaches for improving the corrosion inhibition efficiency.

$\mathrm{SB}$ is as an anodic inhibitor for magnesium alloys. The inhibition efficiency increases with the increased concentration and the elevated temperature. The adsorption process of SB onto magnesium alloys is a spontaneous exothermic process and follows the Temkin adsorption isotherm with negative molecular interaction parameter, which suggests the existence of repulsive forces in the adsorbed layer.

SDBS inhibits both the anodic and cathodic processes simultaneously and acts as a mixed inhibitor for magnesium alloys. The inhibition efficiency increases with the increased concentration and the temperature has little influence on the inhibition efficiency. The adsorption process of SDBS onto magnesium alloys is a spontaneous exothermic process and obeys a Langmuir adsorption isotherm. As a corrosion inhibitor, SDBS is better than SB because of the lower dosage and higher inhibition efficiency.

Compared with the traditional corrosion inhibitors for magnesium alloys such as $\mathrm{Cr}_{2} \mathrm{O}_{7}{ }^{2-}$ and $\mathrm{F}$-, these inhibitors, SDBS and SB, are promising widely used for magnesium alloys because of their advantages of high inhibitive efficiency and environmental friendly property.

It should be pointed that there is much scope for developing the environmental friendly inhibitors for magnesium alloys. One topic of the future investigations is the effect of other green inhibitors, such as the salts of $\mathrm{MoO}_{4}{ }^{2-}$, for magnesium alloys. Another topic is the study on the synergistic effect of the complex corrosion inhibitors. For example, it is helpful to improve the inhibition effect by employing other suitable environmental friendly inhibitors which could be adsorbed onto the magnesium surface, weaken or remove the repulsive forces in the adsorbed layer of SB and make the protective layer more compact. The development of high efficiency environmental friendly inhibitors for magnesium alloys will fasten the engineering applications of magnesium alloys in a larger scale.

\section{Acknowledgments}

This work was sponsored by the Natural Science Foundation Project of CQ (CSTC2009BA4023), the National Natural Science Foundation of China (NSFC20803097), the National Science Fund for Distinguished Young Scholars of China (50725413) and the Fundamental Research Funds for the Central Universities (CDJRC 10220002). 


\section{References}

Afshari, V. \& Dehghanian, C. (2010). Inhibitor effect of sodium benzoate on the corrosion behavior of nanocrystalline pure iron metal in near-neutral aqueous solutions. Journal of Solid State Electrochemistry, 14, 1855-1861, ISSN 1432-8488.

Atkins, P. \& Paula, J. (2006). Physical chemistry (8th Ed.), Oxford University Press, ISBN 9780198700722, Oxford.

Bard, A. \& Fanlkner, L. (2001). Electrochemical methods, fundamentals and applications, John Wiley \& Sons, Inc., ISBN 0-471-04372-9, New York.

Cao, C. \& Zhang, J. (2002). Introduction of electrochemical impedance spectroscopy, Science Press of China, ISBN 7-03-009854-4, Beijing.

Cao, X.; Jahazi, M.; Immarigeon, J.; et al. (2006). A review of laser techniques for magnesium alloys. Journal of Materials Processing Technology, 171, 188-204, ISSN 0924-0136.

Galio, A.; Lamaka, S.; Zheludkevich, M.; et al. (2010). Inhibitor-doped sol-gel coatings for corrosion protection of magnesium alloy AZ31. Surface \& Coatings Technology, 204, 1479-1486, ISSN 0257-8972.

Gary, J. \& Luan, B. (2002). Protective coating on magnesium and its alloys - a critical review. Journal of Alloys and Compounds, 336, 88-113, ISSN 0925-8388.

Li, L; Yao, Z.; Lei, J.; et al. (2009). Adsorption and corrosion inhibition behavior of sodium dodecylbenzenesulfonate on AZ31magnesium alloy. Acta Physico-Chimica Sinica, 25, 1332-1336, ISSN 1000-6818.

$\mathrm{Mu}, \mathrm{G} . ; \mathrm{Li}, \mathrm{X}$; $\mathrm{Liu}, \mathrm{G}$. (2005). Synergistic inhibition between tween 60 and $\mathrm{NaCl}$ on the corrosion of cold rolled steel in 0.5M sulfuric acid. Corrosion Science, 47, 1932-1952, ISSN 0010-938X.

Papavinasam, S. (2000). Corrosion inhibitors, In: Uhlig's corrosion handbook (2nd Ed.), Ravie, R. (Ed.), 1089-1105, John Wiley \& Sons, Inc., ISBN 0-471-15777-5, New York.

Roberge, P. (2000). Handbook of corrosion engineering, McGraw-Hill Com. Inc., ISBN 0-07076516-2, New York.

Sahin, M. \& Bilgic, S. (1999). The effect of crotyl alcohol on the corrosion of austenitic chromium-nickel steel. Applied Surface Science, 147, 27-32, ISSN 0169-4332.

Song, G. \& Atrens, A. (2003). Understanding magnesium corrosion. Advanced Engineering Materials, 5, 837-858, ISSN 1616-301X.

Song, G. (2005). Recent progress in corrosion and protection of magnesium alloys. Advanced Engineering Materials, 7, 563-586, ISSN 1616-301X.

Song, G. (2006). The corrosion and protection of magnesium alloys, Chemical Industry Press of China, ISBN 7-5025-8565-6, Beijing.

Staiger, M.; Pietak, A.; Huadmai, J.; et al. (2006). Magnesium and its alloys as orthopedic biomaterials: a review. Biomaterials, 27, 1728-1734, ISSN 0142-9612.

Zhang, J. \& Zhang, Z. (2004). Magnesium alloys and their applications, Chemical Industry Press of China, ISBN 7-5025-5709-9, Beijing. 


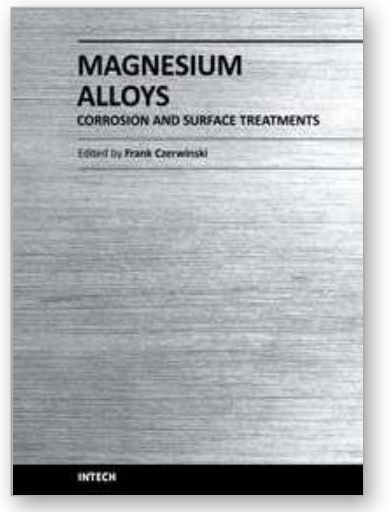

\author{
Magnesium Alloys - Corrosion and Surface Treatments \\ Edited by Frank Czerwinski
}

ISBN 978-953-307-972-1

Hard cover, 344 pages

Publisher InTech

Published online 14, January, 2011

Published in print edition January, 2011

A resistance of magnesium alloys to surface degradation is paramount for their applications in automotive, aerospace, consumer electronics and general-purpose markets. An emphasis of this book is on oxidation, corrosion and surface modifications, designed to enhance the alloy surface stability. It covers a nature of oxides grown at elevated temperatures and oxidation characteristics of selected alloys along with elements of general and electrochemical corrosion. Medical applications are considered that explore bio-compatibility of magnesium alloys. Also techniques of surface modifications, designed to improve not only corrosion resistance but also corrosion fatigue, wear and other behaviors, are described. The book represents a valuable resource for scientists and engineers from academia and industry.

\title{
How to reference
}

In order to correctly reference this scholarly work, feel free to copy and paste the following:

Lingjie Li, Fusheng Pan and Jinglei Lei (2011). Environmental Friendly Corrosion Inhibitors for Magnesium Alloys, Magnesium Alloys - Corrosion and Surface Treatments, Frank Czerwinski (Ed.), ISBN: 978-953-307972-1, InTech, Available from: http://www.intechopen.com/books/magnesium-alloys-corrosion-and-surfacetreatments/environmental-friendly-corrosion-inhibitors-for-magnesium-alloys

\section{INTECH}

open science | open minds

\section{InTech Europe}

University Campus STeP Ri

Slavka Krautzeka 83/A

51000 Rijeka, Croatia

Phone: +385 (51) 770447

Fax: +385 (51) 686166

www.intechopen.com

\section{InTech China}

Unit 405, Office Block, Hotel Equatorial Shanghai

No.65, Yan An Road (West), Shanghai, 200040, China

中国上海市延安西路65号上海国际贵都大饭店办公楼 405 单元

Phone: +86-21-62489820

Fax: +86-21-62489821 
(C) 2011 The Author(s). Licensee IntechOpen. This chapter is distributed under the terms of the Creative Commons Attribution-NonCommercialShareAlike-3.0 License, which permits use, distribution and reproduction for non-commercial purposes, provided the original is properly cited and derivative works building on this content are distributed under the same license. 